\title{
Effect of harvesting time on yield and sown quality of spring cereals during storage
}

\author{
Olga Snigireva* \\ Federal Agricultural Research Center of the North-East named N.V. Rudnitsky, 610007 Kirov, \\ Russian Federation
}

\begin{abstract}
It is important to correctly determine the stage of harvesting. To establish full ripeness, it is necessary to accurately identify the period when plastic substances stop entering the grain. All this is necessary for the formation of high-quality grain. Due to the long-term storage of grain, its germination decreases, as there are violations in the processes of metabolism. Therefore, during the storage period, it is necessary to control the quality of the seed material. The purpose of the research was to determine the impact of harvesting time and long-term storage of grain for obtaining seed material with high indicators of yield and sowing qualities. The experimental part of the work was carried out on the experimental field and in the laboratory conditions of the FGBNU FANC North-East in 2015-2020. From each variant of the experiment, $1 \mathrm{~kg}$ of seeds of the 2015 harvest were stored. Under laboratory conditions, the germination energy and laboratory germination capacity of the seeds were tested. In 2020, field germination and yield qualities of seeds were studied in three-fold repetition on meter plots. During the years of research, changes in the sowing qualities of seeds obtained during storage in 2015 were noted. Seeds from crops that were harvested at the onset of the full ripeness phase and at a grain moisture content of $17 \ldots 20 \%$, (1), the indicators of germination energy and germination were the highest than when harvested at a later time. A significant decrease in indicators was noted in the cleaning options for 10 and 15 days later than the optimal one. The study of the influence of the harvest year and the duration of seed storage showed that seeds 1 and 2 of the harvest period in 2015 provide a higher yield than seeds 3 and 4 of the harvest period. The use of late-harvest seeds in sowing leads to a decrease in the weight of 1000 grains and the nature of the grain.
\end{abstract}

\section{Introduction}

On seed crops, it is necessary to apply the best agrotechnical systems and the correct combination of all its links. To produce high quality seeds of spring cereals, favorable growing conditions are necessary. These conditions determine grain formation, filling and ripening. Grain, which is grown under favorable conditions, retains genotypic features and advantages, acquires excellent sowing and crop qualities [1].

\footnotetext{
*Corresponding author: snigireva_olga@mail.ru
} 
It is important to determine the harvest stage correctly. At the same time, it is necessary to timely both start harvesting at the most appropriate time, and finishes it. Improper, untimely harvesting can nullify all efforts to grow high-quality grain. Too early mowing leads not only to a shortage of grain yields but also to a significant loss of quality. Delays in mowing can also lead to a decrease in the yield and technological parameters of the grain. An incorrect choice of harvesting time can lead to a decrease in the yield, the addition of which was obtained due to the best practices of agrotechnic. The loss of the seed yield is 59\% when harvested 10-15 days after the onset of complete ripeness. Loss must be avoided during harvesting, and this is one of the most important sources for increasing the seed production plan. [2, 3, 4].

After the flowering stage, plastic substances that have accumulated in vegetative organs enter the grain. As a result, the increase in grain weight occurs due to a reduction in the vegetative mass of the plant. To establish absolute ripeness, it is necessary to accurately identify the period when plastic substances stop entering the seed. All this is necessary for the formation of high-quality grain.

The onset of a period of significant accumulation of nutrients depends on climatic characteristics of the zone of spring cereals cultivation [5,6]. Yield losses depend not only on weather conditions but also on the characteristics of the species and cultivar. Weather conditions stretche negatively the process of grain ripening. They make the maturation stage longer. Both in early harvesting, and in late harvesting the quality of seeds decreases $[3,7]$.

The ability to maintain quality, health and nutritional value of grain depends not only on the production and harvest conditions but also on the storage (maintenance of proper storage conditions). Due to the long storage, grain germination ability decreases, as there are disorders in the metabolism processes. Therefore, during the storage period, it is necessary to monitor the quality of the seed material. Even if the germination ability of seeds has decreased insignificantly, then decay processes are already taking place in them $[8,9,10,11,12,13]$. Chromosome decay processes, loss of mitochondria respiratory activity, increased permeability of biomembranes, appearance of toxic products due to metabolic disorders, breakdown of hormones, carbohydrates and self-oxidation of storage lipids necessary for germination, protein denaturation - all this exposes seeds to enter a state of destruction [14].

The purpose of the research is to determine the influence of harvesting time and longterm storage of grain on obtaining of seed material of spring grain crops with high parameters of yield and sowing qualities.

\section{Materials and methods}

The experimental part of the work was carried out on an experimental field and in the laboratory conditions of the Federal Agricultural Research Center of the North-East in 2015-2020. From each variant of the study (harvest time: optimal (control), 5, 10, 15 days after optimal), $1 \mathrm{~kg}$ of seeds harvested in 2015 was laid for storage. In laboratory conditions, a check was carried out in 2016, 2018, and 2020 of germination energy and laboratory germination ability of seeds. In 2020, on meter plots, field germination and yield qualities of seeds were examined in three times repetition.

\section{Results and discussion}

During the years of research, changes in the sowing qualities of seeds were noted in the storage process of seeds obtained in 2015 . Seeds from crops that were removed at the onset 
of the complete ripeness stage and at the grain moisture of $17 \ldots 20 \%$ (variant 1 - control), the germination energy and germination ability parameters were higher than when harvesting at a later time. The most significant decrease of indicators was noted in the variant at harvesting 10 and 15 days later than the optimal (variant 1) except for seeds of barley cv. Rodnik Prikamiya in 2016 of the second term of harvesting (tab. 1). Various studies have noted that harvesting should be carried out within the first five days after the onset of the stage of complete ripeness of grain. This is necessary for obtaining the highest yield of high-quality seeds [8].

Table 1. Influence of harvesting time on sown quality and field germination ability of seeds harvested in 2015 during storage, $\%$.

\begin{tabular}{|c|c|c|c|c|c|c|c|}
\hline \multirow{3}{*}{$\begin{array}{l}\text { Harvesting } \\
\text { time* }\end{array}$} & \multirow{2}{*}{\multicolumn{3}{|c|}{ Germination energy }} & \multicolumn{4}{|c|}{ Germination ability } \\
\hline & & & & \multicolumn{3}{|c|}{ Laboratory } & Field \\
\hline & 2016 & 2018 & 2020 & 2016 & 2018 & 2020 & 2020 г. \\
\hline \multicolumn{8}{|c|}{ Wheat cv. Bazhenka } \\
\hline $1(\mathrm{~K})$ & 97.0 & 93.0 & 80.1 & 98.8 & 95.5 & 89.0 & 49.6 \\
\hline 2 & 94.3 & 79.5 & 48.0 & 96.0 & 82.0 & 59.5 & 37.0 \\
\hline 3 & 91.8 & 21.0 & 3.5 & 94.5 & 32.0 & 10.5 & 11.1 \\
\hline 4 & 87.8 & 19.5 & 2.0 & 91.8 & 22.0 & 2.0 & 13.6 \\
\hline LSD & 7.8 & 3.2 & 1.2 & 6.1 & 4.1 & 1.3 & 2.8 \\
\hline \multicolumn{8}{|c|}{ Barley cv. Rodnik Prikamiya } \\
\hline $1(\mathrm{~K})$ & 91.3 & 84.0 & 51.5 & 93.9 & 89.0 & 57.5 & 42.8 \\
\hline 2 & 93.0 & 70.0 & 36.5 & 95.5 & 75.0 & 39.0 & 32.3 \\
\hline 3 & 90.8 & 6.0 & 1.0 & 93.8 & 8.5 & 2.0 & 7.1 \\
\hline 4 & 84.8 & 1.0 & 0 & 86.5 & 1.0 & 0.5 & 5.5 \\
\hline LSD & 2.4 & 2.1 & 2.3 & 2.1 & 3.6 & 1.3 & 2.4 \\
\hline \multicolumn{8}{|c|}{ Oat cv. Sapsan } \\
\hline $1(\mathrm{~K})$ & 96.0 & 88.5 & 61.5 & 98.0 & 91.0 & 82.5 & 60.5 \\
\hline 2 & 94.3 & 73.5 & 39.5 & 95.8 & 78.5 & 73.0 & 41.7 \\
\hline 3 & 93.8 & 22.0 & 8.5 & 95.0 & 27.0 & 21.0 & 23.5 \\
\hline 4 & 93.3 & 15.0 & 1.5 & 95.0 & 16.5 & 7.5 & 19.5 \\
\hline LSD & 2.1 & 3.4 & 2.2 & 2.6 & 3.1 & 3.1 & 2.8 \\
\hline
\end{tabular}

Note: * $1(\mathrm{~K})$ - control - optimal harvesting time starting from full ripeness stage; 2 - harvesting 5 days after optimal time; 3 - harvesting 10 days after optimal time; 4 - harvesting 15 days after optimal time.

A significant decrease in germination energy in 2020 compared to 2016 was established at a 10-day delay from optimal harvesting time in wheat cv. Bazhenka (by $88.3 \%$ ), in barley cv. Rodnik Prikamiya (by $89.8 \%$ ), in oat cv. Sapsan (by 91.8\%). According to the results of five years of storage, the largest germination energy $(80.1 \%)$ and laboratory germination ability $(89.0 \%)$ in 2020 were in seeds of wheat harvested in an optimally acceptable time.

When estimating the first year of storage, the results of the seed germination energy index of the third and fourth test variants in comparison with the control varied from $0.5 \%$ in barley to $5.2 \%$ in wheat in variant 3 ; and from $2.7 \%$ in oats to $9.2 \%$ in wheat in variant 4 . The assessment of germination energy and laboratory germination ability in 2018 and 2020 showed that the seeds harvested in 2015, obtained when delayed with harvesting for 5-15 days, lost their qualities and switched to the category of forage grain [Russian Federation 
State Standard GOST R 52325-2005]. No germination energy was observed (0\%) when analyzing barley seeds from the variant of 15-day harvest delay.

The greatest depression of laboratory germination ability parameters was noted for seeds of barley cv. Rodnik Prikamiya; according to 2020 data, germination ability varied from $57.5 \%$ for seeds of optimal harvesting time to $0.5 \%$ for seeds obtaining at harvesting after 15 days from optimal time. Similarly observed for seeds of covered oat cv. Sapsan. Seeds of wheat cv. Bazhenka had higher laboratory germination rates. According to the results of the 2018 inspection, the parameter for seeds $(95.5 \%)$ of the optimal harvesting time was in accordance with GOST R 52325-2005; in 2020 it amounted to $89.0 \%$, which allows to use the seeds of this variant for sowing in conditions of a limited growing season of the Kirov region unfavorable for the formation of high quality seeds in accordance with the annual order of the Ministry of Agriculture and Food of the Kirov region, which determines the minimum germination ability of seeds in the level of $89 \%$.

The level of yield of spring cereals in the studies was determined by crop requirements for environmental factors and cultivar features. In May, hydrothermal conditions were favorable for seed germination and the formation of high total plant stand. The conditions of the "germination - heading - earing" period were generally favorable, but at the time of flowering and grain formation (the first - second ten-day period of July) an increased temperature background and insufficient moisturization was noted, especially from the second five-day period of July, when the temperature exceeded the climatic norm by 3-12 ${ }^{\circ} \mathrm{C}$ and reached $34{ }^{\circ} \mathrm{C}$ and $35-36{ }^{\circ} \mathrm{C}$ which led to the sterilization of part of the flowers and negatively affected the yield.

A study of the effects of the harvest year and the duration of seed storage showed that seeds of 1-st and 2-nd harvesting time of 2015 provide higher yields than seeds of 3-rd and 4-th harvesting time (tab. 2). The highest yield of barley cv. Rodnik Prikamiya was obtained in 2020 when using seeds of 2015 harvesting year obtained at optimally acceptable harvesting time and on the fifth day after it (4.0 and 3.9 tons/ha, respectively). A lower yield relative to barley and wheat was formed by oats - a crop of less droughtresistance than wheat and barley (2.4 and 2.1 tons/ha). The values of yields obtained at sowing of 2015 seeds of 3-rd and 4-th variants were quite close for the studied crops.

Table 2. Influence of harvesting time on yield, 1000-grain weight, and volume weight of spring crops stored in 2015.

\begin{tabular}{|c|c|c|c|c|c|c|}
\hline \multirow{2}{*}{$\begin{array}{c}\text { Harvesting } \\
\text { time* }\end{array}$} & \multicolumn{2}{|c|}{ Yield capacity, t/ha } & \multicolumn{2}{c|}{1000 -grain weight, g } & \multicolumn{2}{c|}{ Volume weight, g/l } \\
\cline { 2 - 7 } & 2015 & 2020 & 2015 & 2020 & 2015 & 2020 \\
\hline \multicolumn{7}{|c|}{ Wheat cv. Bazhenka } \\
\hline $1(\mathrm{~K})$ & 3.7 & 3.0 & 39.4 & 39.6 & 826 & 764 \\
\hline 2 & 3.6 & 2.9 & 39.1 & 38.9 & 815 & 762 \\
\hline 3 & 3.5 & 2.5 & 38.7 & 37.5 & 799 & 748 \\
\hline 4 & 3.5 & 1.5 & 38.8 & 36.6 & 800 & 730 \\
\hline LSD & 0.1 & 0.1 & 0.2 & 0.3 & 1.3 & 1.4 \\
\hline \multicolumn{7}{|c|}{ Barley cv. Rodnik Prikamiya } \\
\hline $1(\mathrm{~K})$ & 4.8 & 4.0 & 51.9 & 49.7 & 662 & 648 \\
\hline 2 & 4.8 & 3.9 & 51.4 & 51.8 & 659 & 656 \\
\hline 3 & 4.5 & 2.1 & 50.3 & 46.6 & 632 & 648 \\
\hline 4 & 4.3 & 2.3 & 50.0 & 46.1 & 616 & 646 \\
\hline LSD & 0.1 & 0.1 & 0.2 & 0.3 & 1.4 & 1.1 \\
\hline \multicolumn{7}{|c|}{ Oat cv. Sapsan } \\
\hline $1(\mathrm{~K})$ & 5.3 & 2.4 & 39.2 & 39.7 & 484 & 434 \\
\hline
\end{tabular}




\begin{tabular}{|c|c|c|c|c|c|c|}
\hline 2 & 5.3 & 2.1 & 38.2 & 38.9 & 481 & 434 \\
\hline 3 & 5.0 & 1.9 & 37.3 & 37.4 & 477 & 424 \\
\hline 4 & 5.0 & 2.0 & 37.1 & 35.8 & 456 & 424 \\
\hline LSD & 0.1 & 0.2 & 0.4 & 0.3 & 1.1 & 0.7 \\
\hline
\end{tabular}

Note: * - $1(\mathrm{~K})$ - control - optimal harvesting time starting from full ripeness stage; 2 - harvesting 5 days after optimal time; 3 - harvesting 10 days after optimal time; 4 - harvesting 15 days after optimal time.

With prolonged overexposure of grain on the stem, when it is already fully ripe, its germination occurs, the 1000-grain weight and volume weight as well as a number of other indicators also decrease. This is due to over wetting of grain, as a result of which respiration (redox processes) and the negative effect of the pathogenic complex are increased. It was found that seeds obtained from 2015 harvest's variants of harvesting delays on 5,10 , and 15 days have significantly lower 1000-grain weight than the control; the exception was the barley cv. Rodnik Prikamiya obtained in the variant of use in sowing seeds harvested 5 days later than control. The most significant decrease in the 1000-grain weight was noted for three spring crops when evaluating seeds obtained from variants with harvest delayed by 15 days (by 3.0-3.9 g). Analysis of the 1000-grain weight indicates a high stability of the sign in wheat cv. Bazhenka and oat cv. Sapsan, unlike barley cv. Rodnik Prikamiya, which was harvested in earlier terms and more favorable environmental factors.

In our studies, the volume weight of wheat grain according to the results of 2015 and 2020 was higher than the volume weight of barley and oats. The decrease of the parameter in spring wheat of the 2020 harvest year ranged from $51 \mathrm{~g} / 1$ in variant 3 to $70 \mathrm{~g} / \mathrm{ha}$ in variant 4 relative to the level of 2015. This can be due to the use in 2015 sowing of seed of only one variant - the optimal harvesting time; the conditions of the year of production and the period of seed harvesting; and peculiarities of the crop. The volume weight of grain of barley cv. Rodnik Prikamiya and oat cv. Sapsan was lower than the parameter of wheat cv. Bazhenka; but the dependence of the decrease in the parameter on the harvesting time in 2015 remained, with the exception of 3-rd and 4-th variants in barley, where volume weight was higher than in 2015.

\section{Conclusions}

The sown qualities of spring cereal seeds - wheat, barley and oats, obtained in the conditions of the Kirov region and harvested at optimal ripening time meet the requirements of Russian Federation State Standard GOST R-2005 during 3 years of storage and ensure higher yields, in comparison with seeds obtained when delayed with harvesting for 5-15 days. When developing insurance seed funds of spring cereals, it is necessary to use seeds that are harvested in the first five days after the onset of the absolute ripeness stage. If seeds are deposited from crops harvested 10 and 15 days after the most optimally selected time, there is a powerful and fastest decrease in germination energy, laboratory and field germination abilities. When using in sowing seeds obtained from variants with late harvesting times, it leads to a decrease in the 1000-grain weight and volume weight.

\section{Acknowledgment}

The research was carried out under the support of the Ministry of Science and Higher Education of the Russian Federation within the state assignment of Federal Agricultural Research Center of the North-East named N.V. Rudnitsky (theme No. 0528-2019-0093) 


\section{References}

1. S.G. Lomakin, V.E. Berdyshev, Agroengineering, 4, 11-15 (2015)

2. M. Singh, A. Chauhan, R. Kumar, D. Joshi, P.G. Soni, V.K. Meena, Agricultural Reviews, 38(2), 159-164 (2017)

3. A.S. Golovach, Russian agricultural science review, 7(1), 77-90 (2015)

4. A.A. Muratov, P.V. Tikhonchuk, E.V. Tymoshenko, Lee Hunpen, Far Eastern Agrarian Herald, 4(44), (2017)

5. N.V. Stepnykh, E. V. Nesterova, S. D. Gilev, A. M. Zargaryan, Agrarian Herald of the Urals, 197(6), 26-37 (2020)

6. A.A. Muratov, S.E. Nizki, IOP Conference Series: Earth and Environmental Science, 547, 1-9 (2020)

7. A.I. Ryadnov, O.A. Fedorova, Izvestia of the Nizhnevolzhsky agricultural university complex: science and higher vocational education, 2(58), 375-384 (2020)

8. V.I. Levin, S.A. Makarova, Bulletin of Ryazan State Agrotechnological University named after P.A. Kostycheva, 2(10), 26-29 (2011)

9. T.A. Moybenko, A.S. Kazakova, Young Science of the Agrarian Don: Traditions, Experience, Innovations, 1, 60-67 (2017)

10. V. Ziegler, R. T. Paraginski, C. Dietrich, Journal of Stored Products Research, 91, 1-9 (2021)

11. M.E. Merchalova, V.I. Orobinsky, A.P. Tarasenko, Bulletin of the Voronezh State Agrarian University, 3(50), 127-131 (2016)

12. A.Ya. Sotnik, Siberian Bulletin of Agricultural Science, 48(3), 28-33 (2018)

13. S.O. Solberg, F. Yndgaard, Ch. Andreasen, R. Bothmer, I. G. Loskutov, A. Asdal, Frontiers in Plant Science, 1-15 (2020)

14. A.S. Kazakova, S.Yu. Mayboroda, I.V. Yudaev, Bulletin of Agrarian Science of the Don, 1(45), 68-72 (2019) 